\title{
Environmentally sustainable rice husk ash reinforced cardanol based polybenzoxazine bio-composites for insulation applications
}

\author{
K Krishnadevi $^{1} \cdot$ S. Devaraju ${ }^{1} \cdot$ S. Sriharshitha ${ }^{1} \cdot$ M. Alagar $^{2}$ D $\cdot$ Y. Keerthi Priya $^{3}$
}

Received: 22 October 2018 / Revised: 24 February 2019 / Accepted: 19 June 2019 /

Published online: 1 July 2019

(c) The Author(s) 2019

\begin{abstract}
Tri-substituted cardanol based benzoxazine with functionalized rice husk ash (CBz/ FRHA) bio-composites were developed using renewable resource materials, and their thermal, electrical, and biological properties were studied by different analytical methods. The molecular structure of $\mathrm{CBz}$ was confirmed by nuclear magnetic resonance $\left({ }^{1} \mathrm{H}\right.$ NMR) and Fourier transform infrared spectroscopy (FT-IR) techniques. Data resulted from thermal studies indicated that the incorporation of biobased silica reinforcement effectively improved the thermal properties including $T_{\mathrm{g}}$, thermal stability and char yield. Dielectric studies indicate that the bio-based composites possess the lower value of dielectric constant (low $k-2.15$ ) than that of neat matrix (low $k-4.04$ ). Further, the antimicrobial studies were carried out against Bacillus subtilis, Escherichia coli, Klebsiella pneumoniae and Streptococcus bacteria using disk diffusion method and the results obtained confirm that the CBz/FRHA bio-composites possess an improved antibacterial behavior. Data resulted from different studies, and it is suggested that CBz/FRHA based bio-composites can be used as cost competitive materials in the form of adhesives, sealants, encapsulants and matrices for low-k insulation application in the field of microelectronics for highperformance applications.
\end{abstract}

Keywords Tri-substituted $\cdot$ Cardanol-benzoxazine $\cdot$ Rice husk ash $\cdot$ Biocomposites $\cdot$ Thermal stability $\cdot$ Low- $k$ material $\cdot$ Antimicrobial behavior

K Krishnadevi

krishchem05@gmail.com

$\triangle$ M. Alagar

mkalagar@yahoo.com; muthukaruppanalagar@gmail.com

Extended author information available on the last page of the article 


\section{Introduction}

Vegetable oils such as soybean, tung, linseed, rapeseed, castor oil and cashew nut shell oil or cashew nut shell liquid (CNSL) have been used for a wide variety of applications $[1,2]$. Among these, CNSL, an agricultural by-product abundantly available in many parts of the world, is unique since it contains a phenolic moiety with an unsaturated alkyl chain [3-5]. Cardanol is a natural phenol obtained from cashew nut shell liquid (CNSL) [6, 7]. The use of industrial by-products as renewable raw materials for the production of polymers has been receiving worldwide attention to reduce the environmental impact results from petroleum based products [8-11]. The cashew nutshell liquid has attracted a great deal of attention that can be used to produce numerous industrial resins and products [12-16].

Cardanol is used as sustainable raw material source for the production of polymer based industrial products such as laminating resins, polyurethanes based polymers [17], epoxy resins [18, 19], phenolic resins [20], friction linings, surfactants, emulsifiers, paints, varnishes and benzoxazine resins. The development of new polymers, especially those based on renewable raw materials, are warranted to replace petroleum feed stocks.

When compared with other polymers, polybenzoxazine possesses significant advantages due to their enhanced thermal and chemical stability, dimensional and low surface energy [21]. There have been a lot of reports available on the development of benzoxazine monomeric materials to expand the range of their applications [22]. For example, the flexibility of benzoxazine matrix can be improved by copolymerizing with epoxy [23-25] and UP resin with long aliphatic chains and polymerizable groups. In the case of benzoxazines, the requirement of high temperature for ring opening polymerization and their brittle behavior restricts their utility for different industrial applications [26-30].

To alleviate these problems, benzoxazines can be structurally modified or blended with different chemical or polymeric intermediates, crosslinkers, catalysts, etc.. Further, benzoxazines developed from cardanol suffers from thermal stability along with char yield [31] and however, these can be improved by blending cardanol based benzoxazines with chemical modifiers containing rigid aromatic ring, allyl, propargyl, bismaleimide groups or functionalized silica reinforcements, etc.

In the present work, an attempt has been made to develop a bio-based composites using tri-substituted cardanol benzoxazine $(\mathrm{CBz})$ and varying percentage weight ratio of functionalized silica obtained from rice husk ash. The processability, thermal, dielectric and antibacterial properties of the resulting bio-based polybenzoxazine composites were studied by different analytical methods. Data resulted from different studies are correlated, discussed and reported. 


\section{Experimental}

\section{Materials}

Melamine (99\%) and 3-aminopropyltrimethoxysilane (3-APTMS) (99\%) were purchased from Sigma Aldrich, India. Paraformaldehyde and other solvents (AR grade) were purchased from SRL Chemicals, India. Cardanol was procured from Sathya cashew chemicals Pvt. Ltd. Chennai, India.

\section{Preparation of rice husk ash (RHA)}

Rice husk is collected from a local rice mill and washed several times with deionized water. The dried rice husk is burned in an open air. After burning, the residue was crushed to obtain rice husk ash (RHA). The crushed rice husk ash was immersed in $1 \mathrm{M} \mathrm{HCl}$ solution for $5 \mathrm{~h}$. After that the rice husk ash was washed repeatedly several times with deionized water and then dried in an oven at $110{ }^{\circ} \mathrm{C}$ for $48 \mathrm{~h}$. Then, the dried rice husk ash was heated in a ceramic crucible at $350{ }^{\circ} \mathrm{C}$ for $3 \mathrm{~h}$ and $600{ }^{\circ} \mathrm{C}$ for $6 \mathrm{~h}$ in a muffle furnace. The resultant rice husk ash was stored for further use.

\section{Functionalization of rice husk ash (FRHA)}

RHA was functionalized with 3-aminopropyltrimethoxysilane (3-APTMS) (Scheme 1) according to the reported method [32]. $50 \mathrm{~g}$ of rice husk ash is mixed with $400 \mathrm{ml}$ of dried toluene. The mixture is refluxed under nitrogen atmosphere for

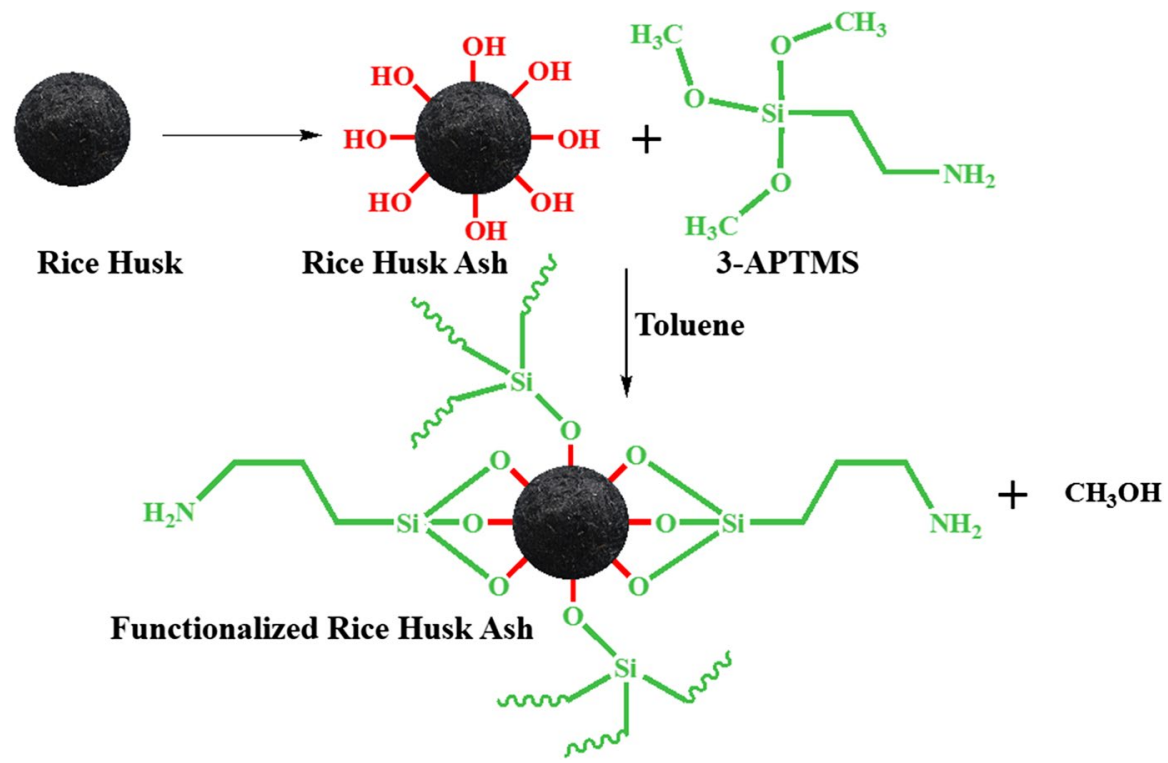

Scheme 1 Functionalization of RHA with APTMS 
$2 \mathrm{~h}$, and then $20 \mathrm{ml}$ of 3-aminopropyltrimethoxysilane (3-APTMS) was added dropwise and allowed to react completely. After, the completion of reaction, the mixture was filtered, washed with ethanol and dichloromethane for several times and then dried at $25{ }^{\circ} \mathrm{C}$ for $24 \mathrm{~h}$. The resultant functionalized rice husk ash (FRHA) was stored for further use.

\section{Synthesis of cardanol-based benzoxazine}

The cardanol-based benzoxazine monomer (Scheme 2) was synthesized using the following procedure. To a solution of melamine $(10 \mathrm{~g}, 0.07 \mathrm{~mol})$ in methanol in water (1:1 ratio), the formaldehyde $(27 \mathrm{~g}, 0.9 \mathrm{~mol})$ was added and stirred for $30 \mathrm{~min}$ at room temperature. Then, cardanol $(134.3 \mathrm{~g}, 0.44 \mathrm{~mol})$ was added to the reaction mixture and stirred for overnight at $85{ }^{\circ} \mathrm{C}$. After the completion of reaction (monitored by TLC), the reaction mixture was extracted with ethyl acetate and washed with $0.5 \mathrm{~N} \mathrm{NaHCO}_{3}$, water and brine solution, and then the product in the form of brownish liquid was collected and preserved (yield 90\%) for further use.

\section{Fabrication of functionalized rice husk ash-incorporated cardanol based benzoxazine (CBz/FRHA) composites}

The CBz/FRHA composites (Scheme 3) were prepared using chloroform as a solvent. Typically, $5 \mathrm{~g}$ of cardanol benzoxazine and varying weight percentages of $1 \mathrm{wt} \%, 5 \mathrm{wt} \% .10 \mathrm{wt} \%, 15 \mathrm{wt} \%$ and $20 \mathrm{wt} \%$ of functionalized rice husk ash (FRHA) were separately dispersed in $20 \mathrm{ml}$ of $\mathrm{CHCl}_{3}$. The cardanol benzoxazine and functionalized rice husk ash (CBz/FRHA) (Scheme 3) were thoroughly mixed with efficient agitation, and then they were separately poured into a silane coated glass plate and cured at $40{ }^{\circ} \mathrm{C}, 60{ }^{\circ} \mathrm{C}, 80^{\circ} \mathrm{C}, 100{ }^{\circ} \mathrm{C}, 120^{\circ} \mathrm{C}, 140{ }^{\circ} \mathrm{C}, 160{ }^{\circ} \mathrm{C}, 180{ }^{\circ} \mathrm{C}, 200{ }^{\circ} \mathrm{C}$,

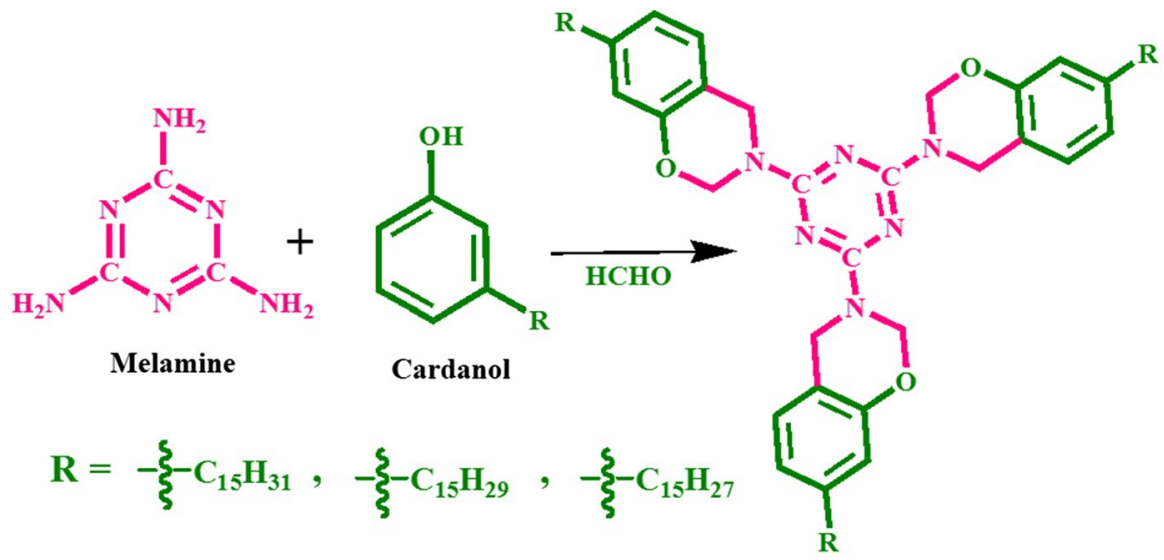

Cardanol based benzoxazine

Scheme 2 Synthesis of cardanol-based benzoxazine $(\mathrm{CBz})$ 


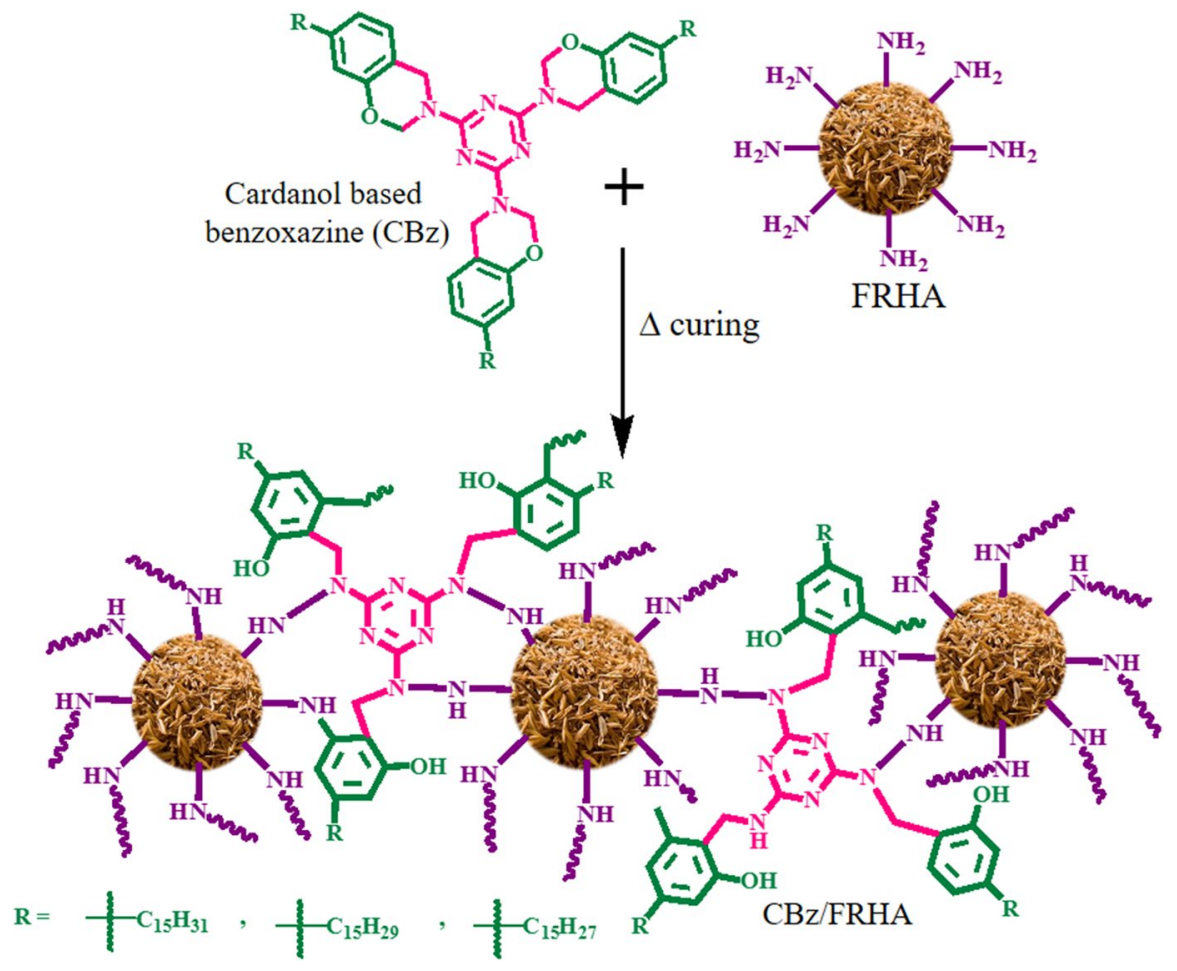

Scheme 3 The proposed schematic representation for the formation of CBz/FRHA composites

$220{ }^{\circ} \mathrm{C}$ for $1 \mathrm{~h}$ each and postcured at $240{ }^{\circ} \mathrm{C}$ for $2 \mathrm{~h}$ to obtain CBz/FRHA bio-composites and were preserved for further studies.

\section{Characterization}

FT-TR spectra were recorded on Perkin Elmer $6 \mathrm{X}$ spectrometer. ${ }^{1} \mathrm{H}$ NMR spectra were recorded with a Bruker $400 \mathrm{MHz}$ using $\mathrm{CDCl}_{3}$ dimethylsulfoxide (DMSOd6) as a solvent and tetramethylsilane (TMS) as an internal standard. The surface morphology of the samples were examined using scanning electron microscope (SEM-EDS; JEOL JSM Model 6360). Element content of RHA and FRHA was examined using energy-dispersive spectroscopy (EDS) analysis (EDAX-EDS-SDD, EDAX Inc., USA (Ametek Inc., Mumbai)). Thermogravimetric analysis (TGA) was performed on Netzsch STA 409 thermogravimetric analyzer under a continuous flow of nitrogen $(20 \mathrm{~mL} / \mathrm{min})$ at a heating rate of $20{ }^{\circ} \mathrm{C} / \mathrm{min}$. Differential scanning calorimetric analysis (DSC) was performed on a Netzsch DSC-200. The samples (about $10 \mathrm{mg}$ in weight) were heated from $25^{\circ} \mathrm{C}$ to $300{ }^{\circ} \mathrm{C}$, and the thermograms were recorded at a heating rate of $10{ }^{\circ} \mathrm{C} / \mathrm{min}$. The vertical burning tests were carried out using a UL-94 vertical flame chamber instrument with sample dimension of $130 \times 13 \times 3 \mathrm{~mm}$ according to the ASTM D3801. The dielectric constant and 
dielectric loss of the samples were measured using a Broad band dielectric spectrometer (BDS-NOVOCONTROL Technologies, Germany) at $35{ }^{\circ} \mathrm{C}$ in the frequency range from $1 \mathrm{~Hz}$ to $1 \mathrm{MHz}$.

The microbial cultures were purchased from microbial type culture collection (MTCC). The common gram positive bacterial culture Streptococcus sps (9724), Bacillus subtilis (1305) and gram negative bacterial culture Escherichia coli (9537) and Klebsiella pneumoniae (10309) were used to test the antibacterial activity of the $\mathrm{CBz} / \mathrm{HPM} / \mathrm{RHA}$ composites. Media and other required chemicals for this study were purchased from Hi-media. Nutrient media were prepared by mixing peptone, beef extract, yeast extract, $\mathrm{NaCl}$ and agar-agar according to standard protocols. $\mathrm{pH}$ of the media was maintained at 7.4. The inocula were prepared by mixing the stain obtained from MTCC in Nutrient agar medium (NAM). 24h old cultures were used for the present study. Nutrient agar plates were prepared, and the bacterial inocula were spread by using the L shaped rod. Wells were made on nutrient agar plates using cork borer. The wells were loaded with different concentrations of the samples DMSO as negative control and standard ampicillin as positive control to compare the zone of inhibition. The plates were sealed with parafilm and incubated at $37{ }^{\circ} \mathrm{C}$ for $24 \mathrm{~h}$. Antimicrobial activity was evaluated by measuring the diameter of inhibition zone in centimeters.

\section{Results and discussion}

\section{Structural characterization}

The molecular structure of functionalized rice husk ask (FRHA) has been confirmed by FT-IR and TGA analysis. Figure 1 shows the FT-IR spectra of RHA and FRHA, the peak appearing at $3245 \mathrm{~cm}^{-1}$ indicates the presence of amino group, and the peak appearing between 1051 and $800 \mathrm{~cm}^{-1}$ confirms the presence of $\mathrm{Si}-\mathrm{O}-\mathrm{Si}$ bonds. The peak appearing at $2933 \mathrm{~cm}^{-1}$ represents the aliphatic group present in FRHA. Thus, these results ascertain that the RHA was functionalized with 3-APTMS. Further the surface modified RHA was confirmed by TGA (Fig. 2). The values of percentage char yield obtained from TGA for RHA and FRHA are 98\% (5\% weight loss due to the moisture in RHA) and $82 \%$, respectively. The lower value of char yield obtained for FRHA infers the occurrence of the decomposition of aliphatic propyl group of 3-APTMS, which in turn ascertains the amino silane functionalization of rice husk ash (FRHA). Further, functionalization of RHA was also confirmed by energy-dispersive spectroscopy (EDS) analysis. Figure 3 and Table 1 show the EDS analysis of RHA and FRHA. From EDS, the elemental weight percentage of carbon (16.76\%) and nitrogen $(2.87 \%)$ were observed for FRHA confirms the effective functionalization of APTMS on the RHA surface.

The $\mathrm{CBz}$ monomer was synthesized using cardanol and melamine by Mannich reaction. Later, the molecular structure of the $\mathrm{CBz}$ monomer was confirmed by FT-IR and NMR techniques. The ${ }^{1} \mathrm{HNMR}$ spectrum of $\mathrm{CBz}$ monomer is presented in Fig. 4. From the NMR, the peak appearing between 6.6 and $7.1 \mathrm{ppm}$ was assigned to the aromatic protons. The peak appearing at $5.6 \mathrm{ppm}\left(\mathrm{O}-\mathrm{CH}_{2}-\mathrm{N}\right)$ 


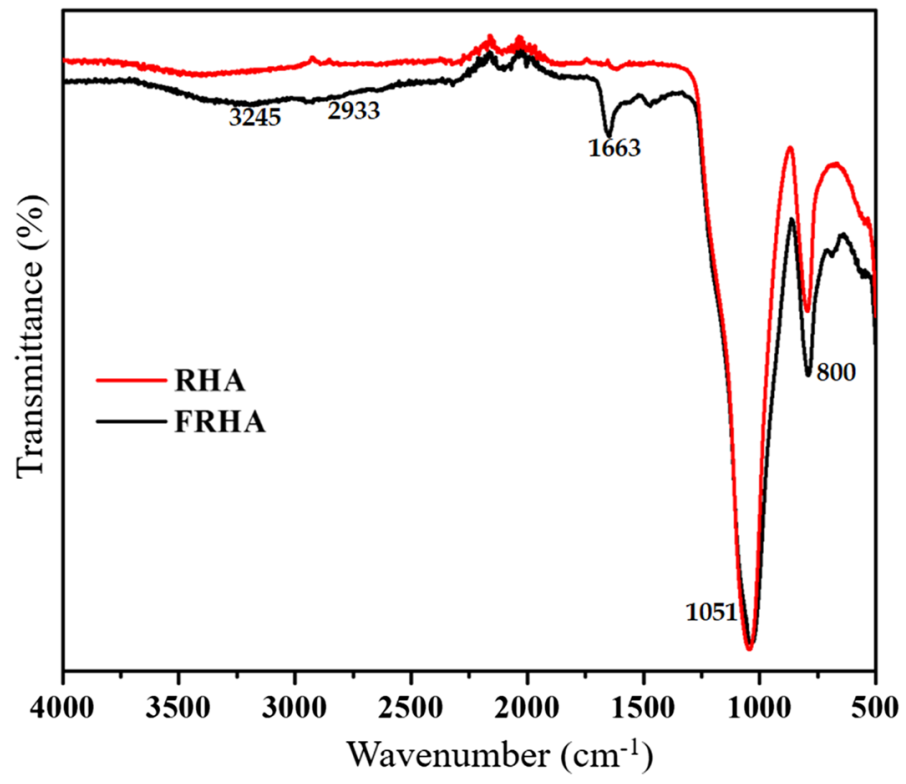

Fig. 1 FT-IR spectra of RHA and FRHA

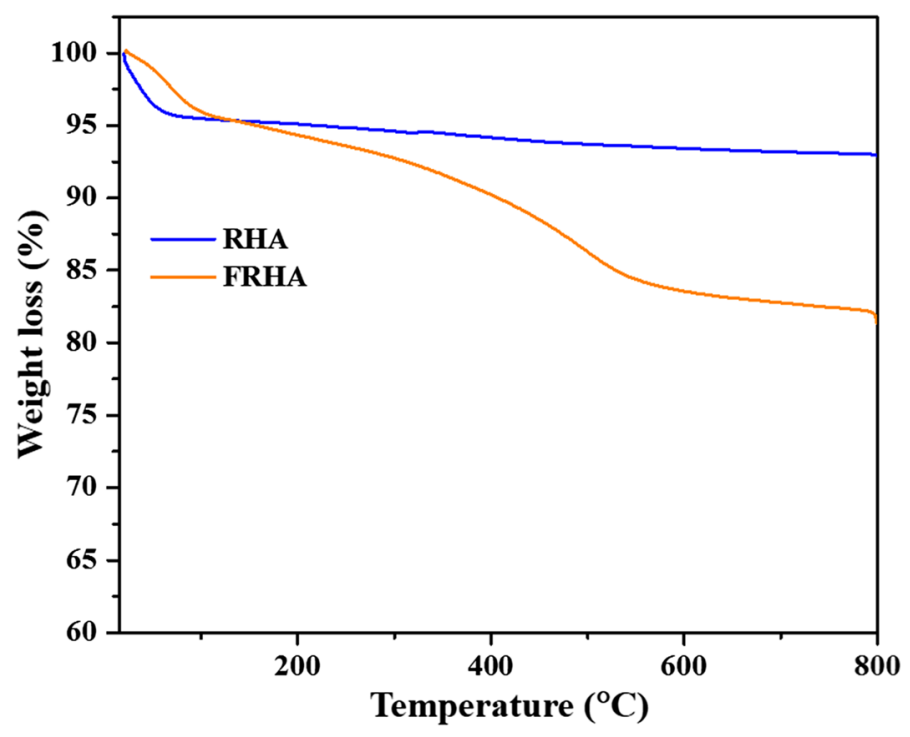

Fig. 2 TGA analysis of RHA and FRHA

and $4.7 \mathrm{ppm}$ corresponds to ph- $\mathrm{CH}_{2}-\mathrm{N}$, confirming the formation of the benzoxazine ring [30]. The peaks appearing at $1.21,1.37,1.57$ and $2.53 \mathrm{ppm}$ were corresponding to aliphatic $-\mathrm{CH}_{2}$ protons of cardanol. The peak present at $4.6-6 \mathrm{ppm}$ 

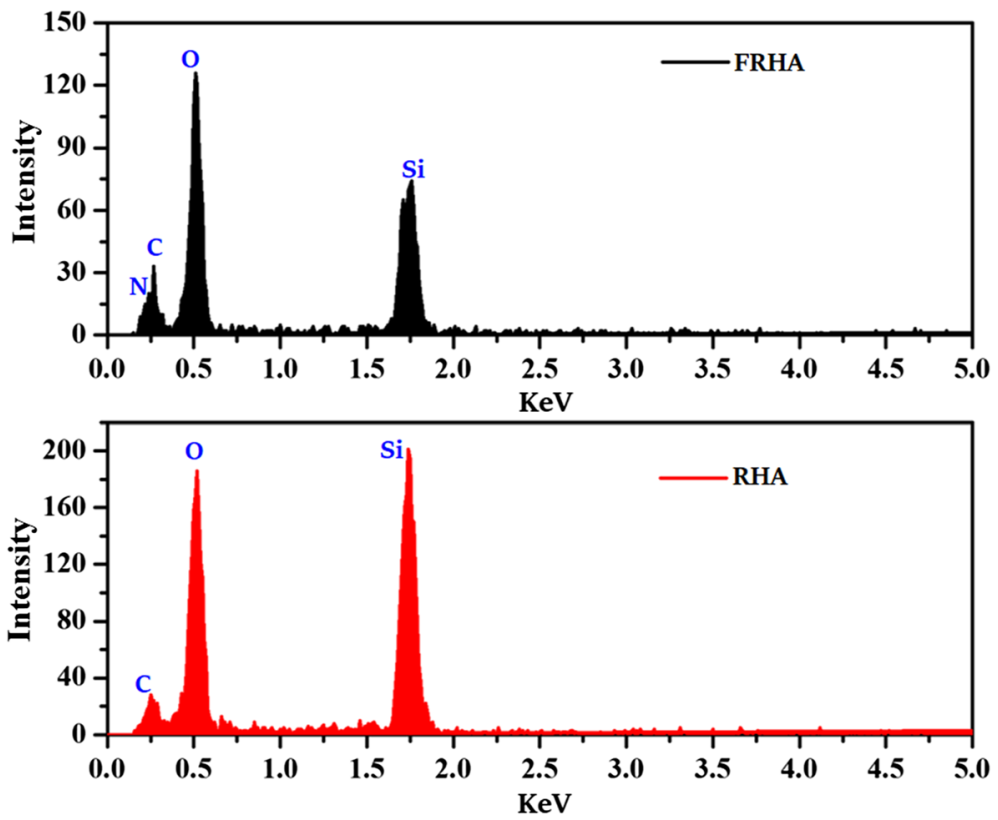

Fig. 3 EDS spectra of RHA and FRHA

Table 1 EDS atomic percentage values of RHA and FRHA

\begin{tabular}{llr}
\hline List of elements & \multicolumn{2}{l}{ Weight percentage $(\%)$} \\
\cline { 2 - 3 } & RHA & FRHA \\
\hline $\mathrm{Si}$ & 51.11 & 37.65 \\
$\mathrm{O}$ & 43.16 & 42.72 \\
$\mathrm{C}$ & 5.73 & 16.76 \\
$\mathrm{~N}$ & - & 2.87 \\
\hline
\end{tabular}

indicates the presence of unsaturated double-bond group in the cardanol. Further, the $\mathrm{CBz}$ structure was confirmed by ${ }^{13} \mathrm{CNMR}$ and is shown in Fig. 5. The signal from $25.60 \mathrm{ppm}$ to $35.85 \mathrm{ppm}$ confirms the presence of aliphatic carbon atoms of cardanol. The oxazine ring formation was confirmed from the presence peaks at $55.53 \mathrm{ppm}$ and $73.07 \mathrm{ppm}$ for $\mathrm{Ph}-\mathrm{CH}_{2}-\mathrm{N}$ and $\mathrm{O}-\mathrm{CH}_{2}-\mathrm{N}$, respectively. The peaks observed from $112.55 \mathrm{ppm}$ to $166.27 \mathrm{ppm}$ confirm the presence of aromatic carbons in the $\mathrm{CBz}$. The peak appeared at $166.27 \mathrm{ppm}$ confirms the presence of $\mathrm{N}-\mathrm{C}-\mathrm{N}$-for melamine core in the $\mathrm{CBz}$. The FT-IR spectrum of $\mathrm{CBz}$ monomer is presented in Fig. 6. The peaks appearing at $1561 \mathrm{~cm}^{-1}$ and $1457 \mathrm{~cm}^{-1}$ confirm the presence of 1,2,4-tri-substituted benzene ring in $\mathrm{CBz}$. The characteristic absorption peaks appearing at $1354 \mathrm{~cm}^{-1}$ and $1150 \mathrm{~cm}^{-1}$ were assigned to asymmetric stretching of $\mathrm{Ar}-\mathrm{O}-\mathrm{C}$ and symmetric stretching of $\mathrm{C}-\mathrm{O}-\mathrm{C}$ in benzoxazine 


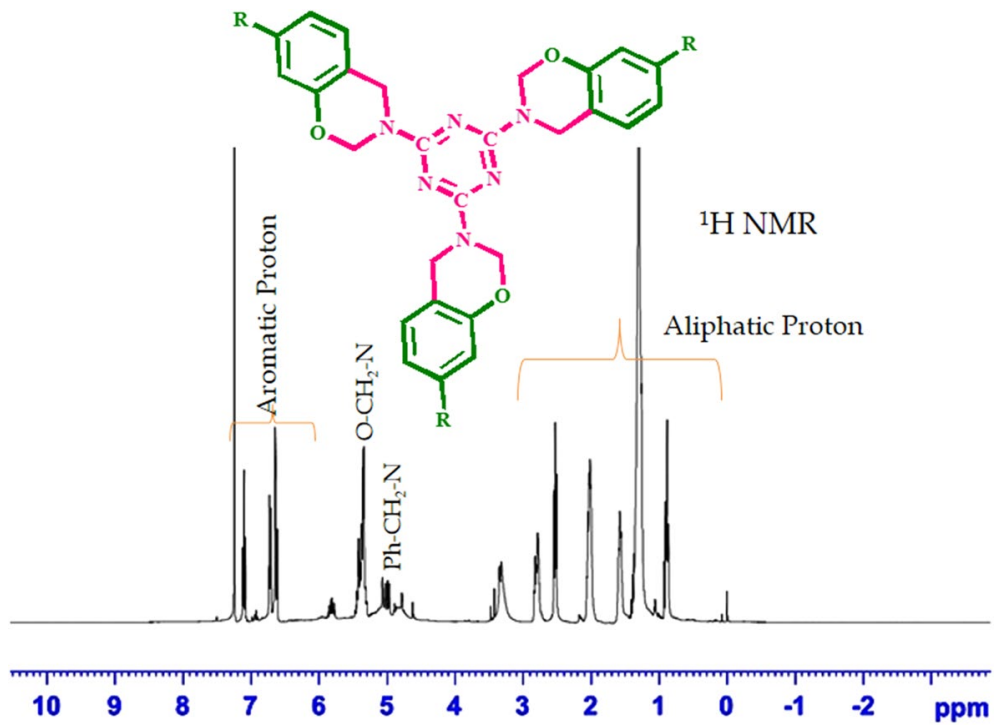

Fig. $4{ }^{1} \mathrm{HNMR}$ spectrum of $\mathrm{CBz}$ monomer

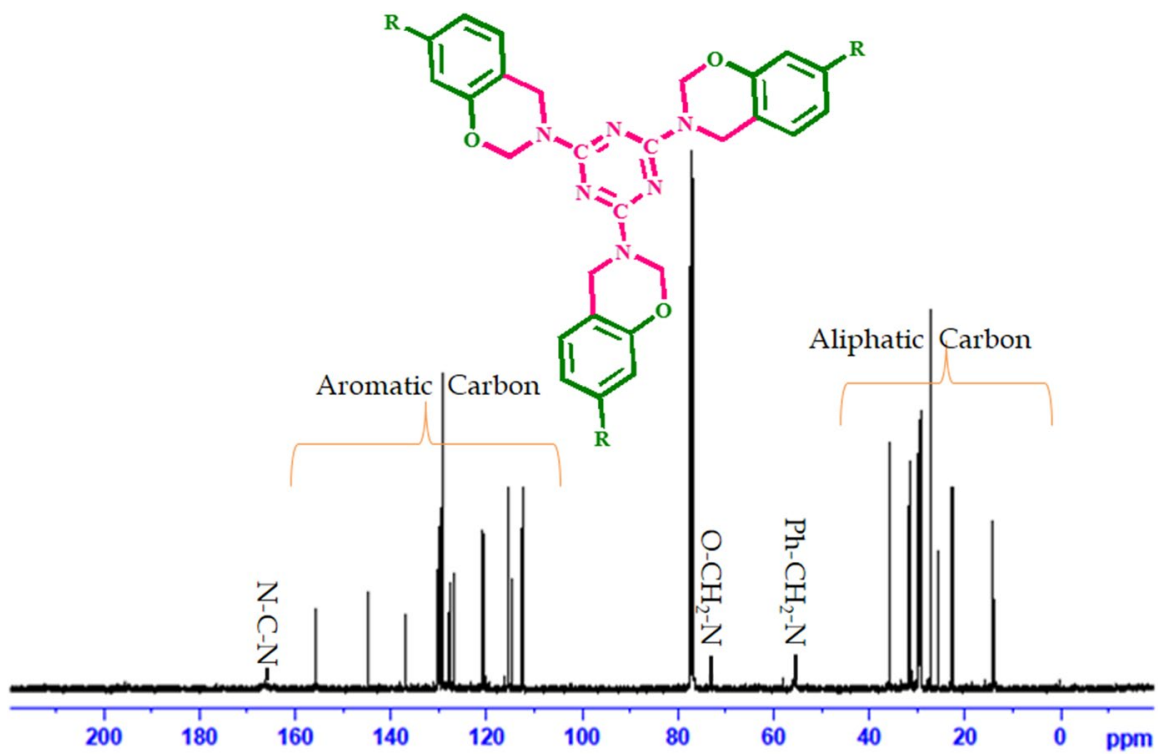

Fig. $5{ }^{13} \mathrm{C}$ NMR spectrum of $\mathrm{CBz}$ monomer

group, respectively. Further, the presence of peak at $923 \mathrm{~cm}^{-1}(\mathrm{~N}-\mathrm{C}-\mathrm{O})$ confirms the structure of the $\mathrm{CBz}$ monomer. The bands appearing at 2924 and $2853 \mathrm{~cm}^{-1}$ represent symmetric and asymmetric stretching of the aliphatic $\mathrm{CH}_{2}$ group in the $\mathrm{CBz}$, respectively. 


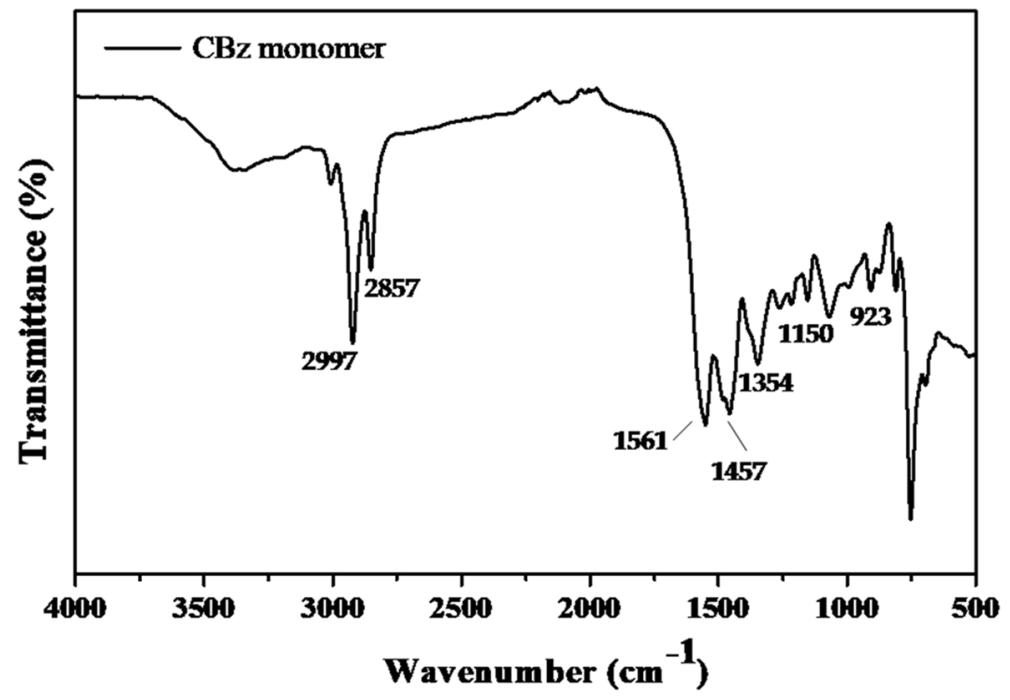

Fig. 6 FT-IR spectrum of $\mathrm{CBz}$ monomer

\section{Curing temperature of $\mathrm{CBz}$}

The curing behavior of synthesized $\mathrm{CBz}$ monomer is analyzed by DSC analysis and is shown in Fig. 7. From the DSC thermogram, the exothermic peak appearing at $229^{\circ} \mathrm{C}$ for $\mathrm{CBz}$ confirms the ring opening polymerization of $\mathrm{CBz}$ benzoxazine. Generally, the ring opening polymerization temperature of cardanol based

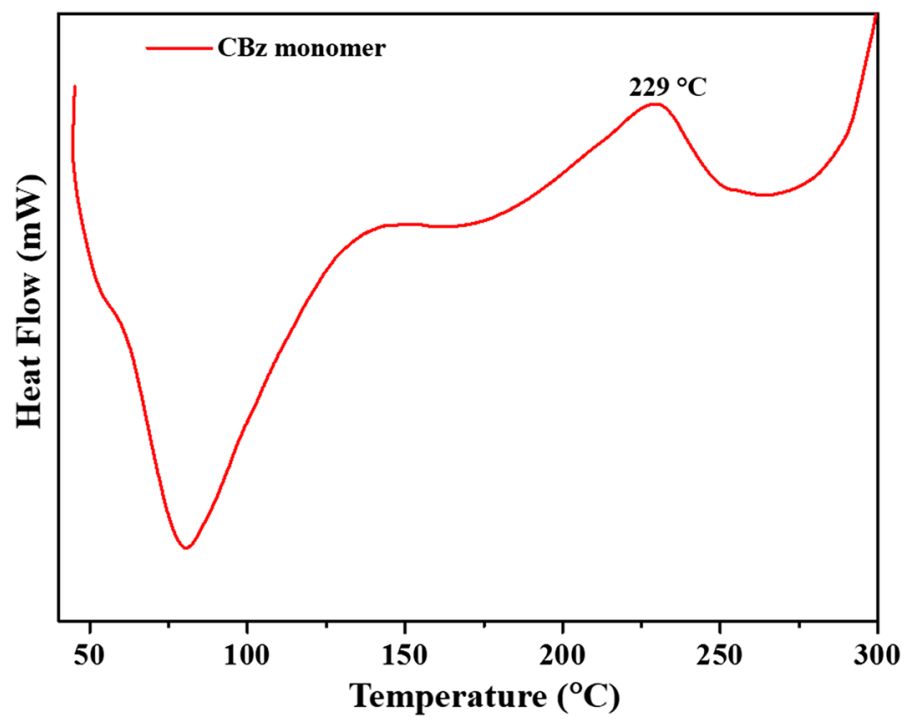

Fig. 7 Curing behavior of $\mathrm{CBz}$ monomer 
benzoxazine was $250{ }^{\circ} \mathrm{C}$. It was noticed that the curing temperature of melaminebased $\mathrm{CBz}$ was observed lower (exotherm maxima $T_{\mathrm{p}}=229{ }^{\circ} \mathrm{C}, T_{\mathrm{i}}=163{ }^{\circ} \mathrm{C}$ and $T_{\mathrm{f}}=259{ }^{\circ} \mathrm{C}$ ) when compared with that of aniline-based cardanol-benzoxazine $\left(275^{\circ} \mathrm{C}\right)$ [32] due to the presence of tri-substituted melamine (heterocyclic) core in the $\mathrm{CBz}$ which in turn contributes to reduction in the curing temperature.

\section{FT-IR spectra of $\mathrm{CBz}$ and $\mathrm{CBz} / \mathrm{FRHA}$ bio-composites}

CBz/FRHA bio-composites were developed through ring opening polymerization by thermal curing. The formation of CBz/FRHA bio-composites was confirmed by FT-IR technique, and the results obtained are shown in Fig. 8. The FT-IR spectra of cured $\mathrm{CBz}$, and CBz/FRHA bio-composites are also presented in Fig. 8. From the figure, the disappearance of peak at $923 \mathrm{~cm}^{-1}$ was noticed, which indicates the oxazine ring opening polymerization of $\mathrm{CBz}$. The peaks observed at 2924 and $2853 \mathrm{~cm}^{-1}$ represent symmetric and asymmetric vibration of aliphatic chain of cardanol moiety, respectively. The appearance of an absorption band at $1269 \mathrm{~cm}^{-1}$ indicates Si-O-Si linkages of symmetric stretching, and appeared at $1021 \mathrm{~cm}^{-1}$ confirms the presence of asymmetric stretching of FRHA group.

Data obtained from FT-IR analysis infer that the benzoxazine undergoes the ring-opening polymerization, generating the phenolic hydroxyl group, which confirms the formation of polybenzoxazine network [33]. From the results obtained, it

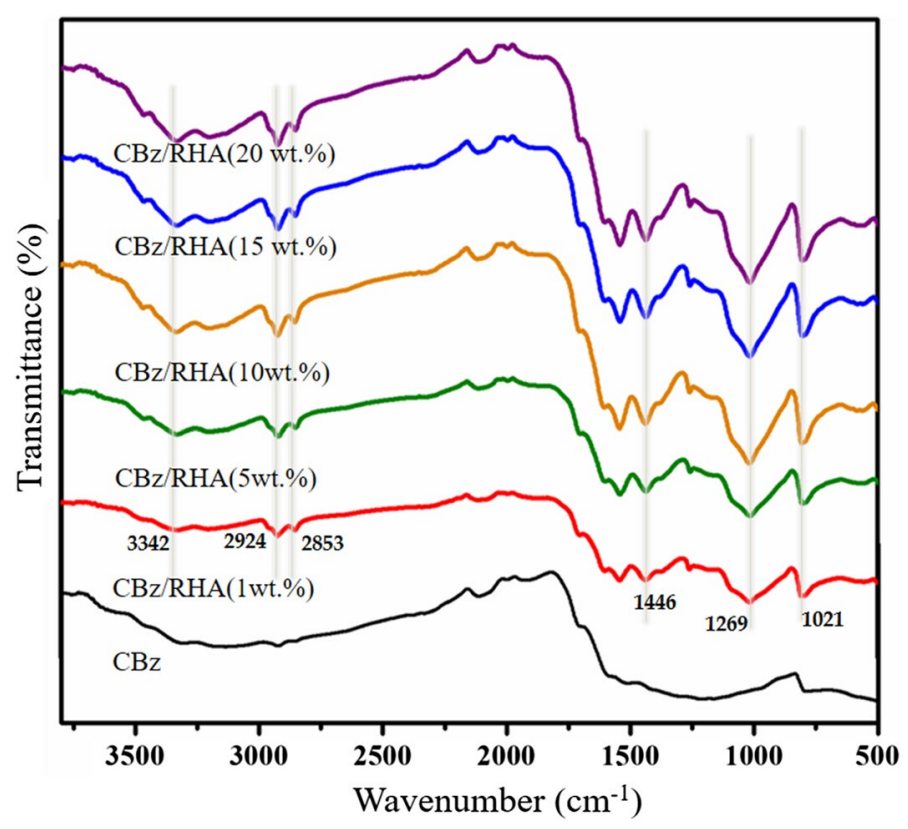

Fig. 8 FT-IR spectra of CBz/FRHA composites 


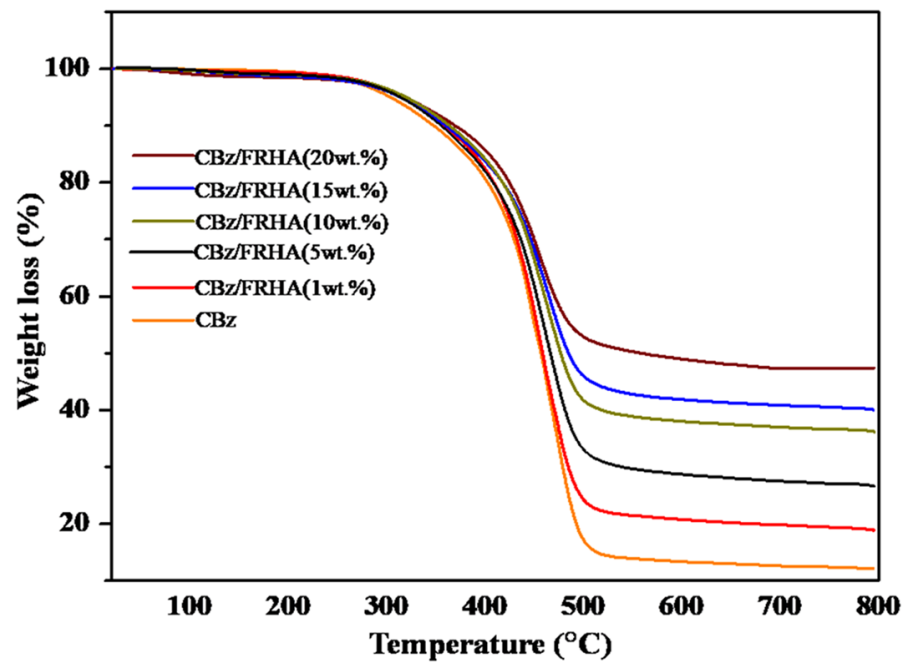

Fig. 9 Thermogravimetric analysis (TGA) of CBz and CBz/FRHA-incorporated polymer composites

Table 2 Thermal stability and LOI values of CBz and CBz/FRHA polymer composites

\begin{tabular}{|c|c|c|c|c|c|c|c|c|}
\hline S. no & Sample & $T_{\mathrm{g}}\left({ }^{\mathrm{o}} \mathrm{C}\right)$ & $\begin{array}{l}5 \% \\
\text { weight } \\
\text { loss }\left({ }^{\circ} \mathrm{C}\right)\end{array}$ & $\begin{array}{l}10 \% \\
\text { weight } \\
\text { loss }\left({ }^{\circ} \mathrm{C}\right)\end{array}$ & $T_{\max }\left({ }^{\circ} \mathrm{C}\right)$ & $\begin{array}{l}\text { Char } \\
\text { yield \% at } \\
800\left({ }^{\circ} \mathrm{C}\right)\end{array}$ & UL-94 test & LOI \\
\hline 1 & $\mathrm{CBz}$ & 129 & 304 & 347 & 444 & 12 & - & 22 \\
\hline 2 & $\begin{array}{c}\text { CBz/FRHA } \\
(1 \text { wt } \%)\end{array}$ & 131 & 307 & 354 & 446 & 18 & - & 25 \\
\hline 3 & $\begin{array}{c}\text { CBz/FRHA } \\
(5 \mathrm{wt} \%)\end{array}$ & 133 & 314 & 357 & 457 & 32 & V-2 & 30 \\
\hline 4 & $\begin{array}{c}\text { CBz/FRHA } \\
(10 \mathrm{wt} \%)\end{array}$ & 136 & 316 & 359 & 460 & 36 & V-2 & 32 \\
\hline 5 & $\begin{array}{c}\text { CBz/FRHA } \\
(15 \mathrm{wt} \%)\end{array}$ & 141 & 317 & 363 & 464 & 40 & V-1 & 34 \\
\hline 6 & $\begin{array}{c}\text { CBz/FRHA } \\
(20 \mathrm{wt} \%)\end{array}$ & 145 & 319 & 370 & 470 & 47 & V-1 & 36 \\
\hline
\end{tabular}

can be concluded that the incorporation of silane functionalized rice husk ash to $\mathrm{CBz}$ can effectively improve the thermal properties of cardanol-benzoxazine [34].

\section{Thermal properties}

The thermal stability and degradation characteristics of neat $\mathrm{CBz}$, and varying weight percentages of FRHA reinforced $\mathrm{CBz}$ bio-composites were characterized using TGA analysis under nitrogen atmosphere, and the results obtained are shown in Fig. 9 and Table 2. The onset temperature for 5\% weight loss and $10 \%$ weight loss obtained was $304-319{ }^{\circ} \mathrm{C}$ and $347-370{ }^{\circ} \mathrm{C}$, respectively, for FRHA-reinforced $\mathrm{CBz}$ 
bio-composites. The maximum degradation temperature $\left(T_{\max }\right)$ of the neat $\mathrm{CBz}$ and $20 \mathrm{wt} \%$ reinforced CBz/FRHA was $444{ }^{\circ} \mathrm{C}$ and $470{ }^{\circ} \mathrm{C}$, respectively. From the TGA, it was noticed that the thermal stability was increased with increasing weight percentages of FRHA [35]. Among them, $20 \mathrm{wt} \%$ of CBz/FRHA biocomposites possesses the highest stability than that of neat matrix and composites and this may be explained due to the formation of complex network structure imparted by silica reinforcement in the system. Further, the FRHA in the $\mathrm{CBz}$ provides an additional heat capacity which alleviates the materials against thermal degradation. Further, it was also observed that the introduction of FRHA into the $\mathrm{CBz}$ matrix, it has reduced the volatile degradation. In addition, silica layer of FRHA can form a passive protective layer on the surface of the $\mathrm{CBz}$ composites, which prevents the further oxidation of the inner part of the matrix, and hence the value of char yield obtained was more than that of RHA reinforcement incorporated [34].

DSC analysis of $\mathrm{CBz}$ and varying weight percentages of FRHA-reinforced biocomposites are carried out over the range of $30{ }^{\circ} \mathrm{C}$ to $300{ }^{\circ} \mathrm{C}$ at the heating rate of $10{ }^{\circ} \mathrm{C}$ per minute, and the results obtained are presented in Table 1 and Fig. 10. It was observed that the value of glass transition temperature $\left(T_{\mathrm{g}}\right)$ of the cardanol benzoxazine matrix and RHA reinforced composites are enhanced according the percentage incorporation of FRHA. This may be due to the formation of network structure which hinders the mobility of the molecules and improves the $T_{g}$ values of both benzoxazine matrix and bio-composites [36].

Flame retardant behavior of cardanol-based polybenzoxazine composites was evaluated by UL-94 vertical burning experiment and LOI, and their results are presented in Table 2. The UL-94 vertical burning result shows that the neat $\mathrm{CBz}$ and CBz/FRHA (1 wt\%) exhibit no rating, whereas V-2 rating was noticed for 5 and 10 wt $\%$ reinforced FRHA-incorporated $\mathrm{CBz}$ composites. V-1 rating was obtained for the samples of 15 and $20 \mathrm{wt} \%$ reinforced FRHA incorporated $\mathrm{CBz}$ composites. The char yield data obtained from TGA analysis were taken to assess the flame retardant behavior of these materials by limiting oxygen index (LOI) analysis using the equation of van Krevelen and Hoftyzer [37].

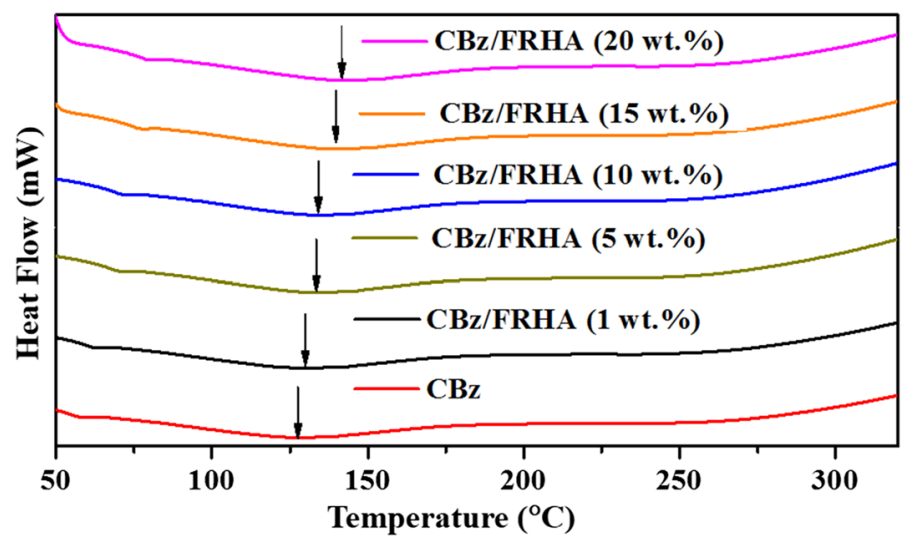

Fig. 10 Differential calorimetric analysis (DSC) of the composites 


$$
\mathrm{LOI}=17.5+0.4 \mathrm{CR}
$$

where $\mathrm{CR}$ is the percentage char yield of polymer remaining at $800{ }^{\circ} \mathrm{C}$. The LOI values calculated for the cured $\mathrm{CBz}$, and varying wt $\%$ of FRHA-reinforced $\mathrm{CBz}$ composites are presented in Table 3. From Table 3, it was observed that the LOI value was increased with increasing weight percentage of FRHA. Among samples studied, 20 wt $\%$ FRHA-reinforced CBz-based bio-composites possess the highest value of LOI of $36 \%$ when compared to that of others. This may due to formation of graphitized carbon residue from the polymeric nature of the samples as well as the inorganic residue obtained from functionalized RHA reinforcement. Hence, the combination of both organic and inorganic residue contributes to the total char yield $(\%)$ of the material. Further, the inorganic passive layer protects further degradation of samples and hence the value of char yield was more than that of reinforcement incorporated. The good intrinsic flame retardant behavior observed was attributed to the existence of nitrogen and siloxane network in the composite materials. The presence of nitrogen core in melamine ring created an inner atmosphere, and $\mathrm{Si}-\mathrm{O}-\mathrm{Si}$ inorganic phase present in the FRHA can promote the formation of intumescent char, which in turn enhances the flame retardancy in the way of a condensed phase. Such a category of a flame retarding mechanism is well known as an intumescent mechanism similar to that of melamine, which provides more inert nitrogen atmosphere and FRHA further promotes an intumescent char layer. From the LOI and UL-94 results, the developed FRHA/CBz bio-composites possess good flame retardant behavior and these materials can be used as an effective flame retardant material for various applications [38, 39].

\section{Scanning electron microscope}

It is well known that the charring structure is one of the most important factors that can be used to assess the flame retardancy behavior. Figure 11 presents the SEM images of FRHA/CBz char residue surface obtained after UL-94 test. From the images, it was observed a carbonaceous structure of dense outer char layer of the composites [34]. Further, the rigid char layer in the FRHA/CBz can serve as a barrier against oxygen diffusion and in turn protects the composites from heat and

Table 3 The values of dielectric constant and dielectric loss

\begin{tabular}{llll}
\hline S. no & Sample & $\begin{array}{l}\text { Dielectric } \\
\text { constant }\left(\varepsilon^{\prime \prime}\right) \text { at } \\
1 \mathrm{MHz}\end{array}$ & $\begin{array}{l}\text { Dielectric loss } \\
\left(\varepsilon^{\prime \prime}\right) \text { at } 1 \mathrm{MHz}\end{array}$ \\
\hline 1 & $\mathrm{CBz}$ & 4.04 & 0.0034 \\
2 & CBz/FRHA (1 wt\%) & 3.52 & 0.0030 \\
3 & CBz/FRHA (5wt\%) & 2.89 & 0.0026 \\
4 & CBz/FRHA (10 wt\%) & 2.63 & 0.0021 \\
5 & CBz/FRHA (15 wt\%) & 2.29 & 0.0017 \\
6 & CBz/FRHA (20wt\%) & 2.15 & 0.0015 \\
\hline
\end{tabular}



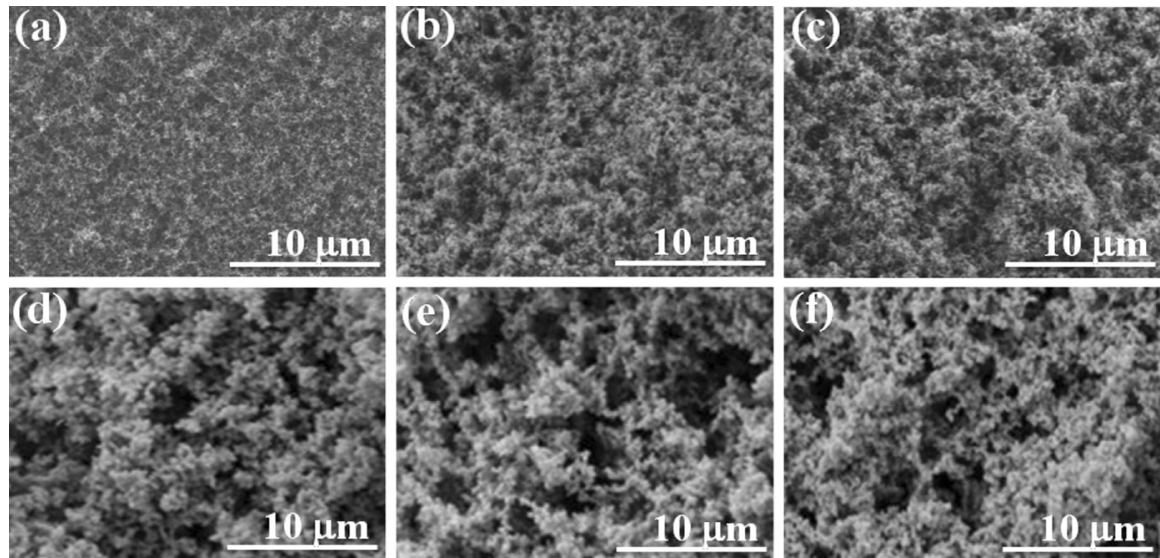

Fig. 11 SEM images of char residue after burning of a $\mathrm{CBz}, \mathbf{b} \mathrm{CBz} / \mathrm{FRHA}$ (1 wt\%), c CBz/FRHA (5 wt $\%$ ), d CBz/FRHA (10 wt \%), e CBz/FRHA (15 wt \%), f CBz/FRHA (20 wt \%) polymer composites

burning [38]. From the images, it is confirmed that the incorporation of silane functionalized rice husk ash into the cardanol-based benzoxazine appreciably improved the flame retardant properties.

\section{Dielectric constant and loss}

The values of dielectric constant and dielectric loss of composites depend on the presence of dipole, electronic, atomic polarization, inter and intramolecular hydrogen bonding, which can influence the change in polarization throughout the polymer composite network. In addition, the intermolecular hydrogen bonding obviously can enhance the polarization and dielectric constant, whereas the formation of intramolecular hydrogen bonding contributes to reduce the value of dielectric constant [40, 41]. Figure 12 and Table 3 present the values of dielectric constant and
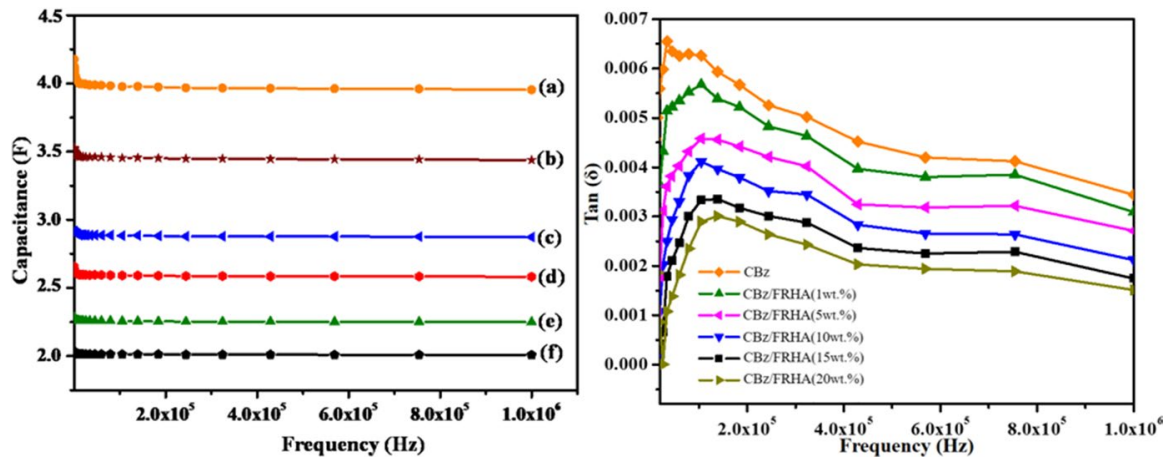

Fig. 12 Dielectric constant and loss of a CBz, b CBz/FRHA (1 wt\%), c CBz/FRHA (5 wt\%), d CBz/ FRHA (10 wt $\%$ ), e CBz/FRHA (15 wt $\%$ ), f CBz/FRHA (20 wt \%) composites 
dielectric loss of $\mathrm{CBz}$, and varying weight percentages of $\mathrm{CBz} / \mathrm{FRHA}$ composites; from the results, it was observed that the increased incorporation of FRHA to the cardanol benzoxazine influences the insulation behavior of resulting composites. It is also clear that the value of dielectric constant decreased with increasing weight percentage of FRHA. In general, the presence of alkyl moiety, flexible bridging units and bulky groups which limit chain packing density for to enhance the free volume of composites [41]. From data obtained from the present study, it may be explained that the reinforcement of functionalized rice hush ash into cardanol-benzoxazine lowers the values of dielectric constant and dielectric loss due to the formation of less polar network structure with enhanced intramolecular hydrogen bonding within the composite systems.

\section{Antimicrobial study of the CBz/FRHA composites}

Antimicrobial activity of $\mathrm{CBz}, \mathrm{FRHA}$ and $\mathrm{CBz} / \mathrm{FRHA}$ different ratios was carried out against gram-positive bacterial culture Streptococcus, Bacillus subtilis and gram-negative bacterial culture Escherichia coli and Klebsiella pneumoniae by using well diffusion method. Table 4 and Fig. 13 show the diameter $(\mathrm{cm})$ of inhibition zones on agar plates after $24 \mathrm{~h}$ of incubation at $37{ }^{\circ} \mathrm{C}$ for antibacterial activity. The cardanol-based benzoxazine incorporated rice husk ash (CBz/FRHA) shows good antibacterial activity than that of $\mathrm{CBz}$. The antibacterial activity increased with the increase in the concentration of FRHA and the CBz/FRHA (20wt\%) sample exhibits better bacterial effect and this may be explained due to the existence of van der Waal's forces of attraction $[42,43]$ between the composites and the bacterial surface. The antibacterial activity of benzoxazine composites is mainly influenced by the presence of siloxane and oxazine skeletons and leaching of minerals, proteins, genetic materials which consequently led to death (Fig. 14) of the cells.

\section{Conclusion}

In the present work, a tri-substituted cardanol-based benzoxazine $(\mathrm{CBz})$ was synthesized using melamine and formaldehyde. The neat $\mathrm{CBz}$ benzoxazine was reinforced varying weight percentages of functionalized rice husk ash in order

Table 4 Antimicrobial studies of the polymer composites

\begin{tabular}{llllll}
\hline S. no & Name of the organism & B. Subtilis & E. Coli & K. Pneumoniae & Streptococcus \\
\hline 1 & CBz & 1.1 & 1.4 & 1.2 & 0.9 \\
2 & CBz/FRHA (1 wt\%) & 1.5 & 1.6 & 1.4 & 1.2 \\
3 & CBz/FRHA (5 wt\%) & 1.7 & 1.7 & 1.5 & 1.5 \\
4 & CBz/FRHA (10 wt\%) & 1.6 & 1.8 & 1.6 & 1.6 \\
5 & CBz/FRHA (15 wt\%) & 1.7 & 2.0 & 1.7 & 2.2 \\
6 & CBz/FRHA (20 wt\%) & 1.8 & 2.3 & 2.5 & 2.5 \\
\hline
\end{tabular}




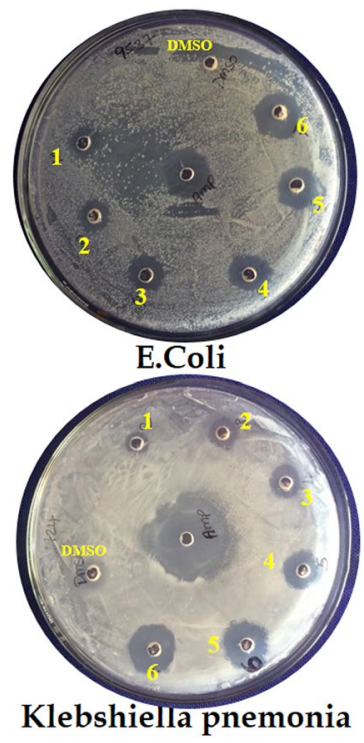

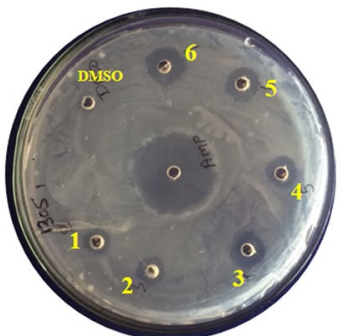
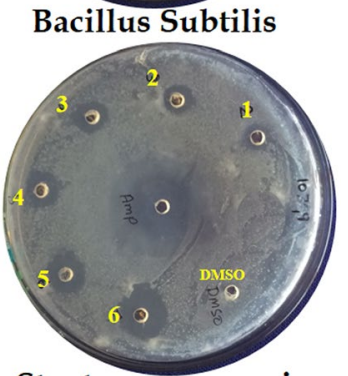

Steptococcus species

Fig. 13 Antimicrobial studies of (1) CBz, (2) FRHA, (3) CBz/FRHA (1 wt\%), (4) CBz/FRHA (5 wt\%), (5) CBz/FRHA (10 wt \%), (6) CBz/FRHA (15 wt\%), (7) CBz/FRHA (20 wt \%) composites

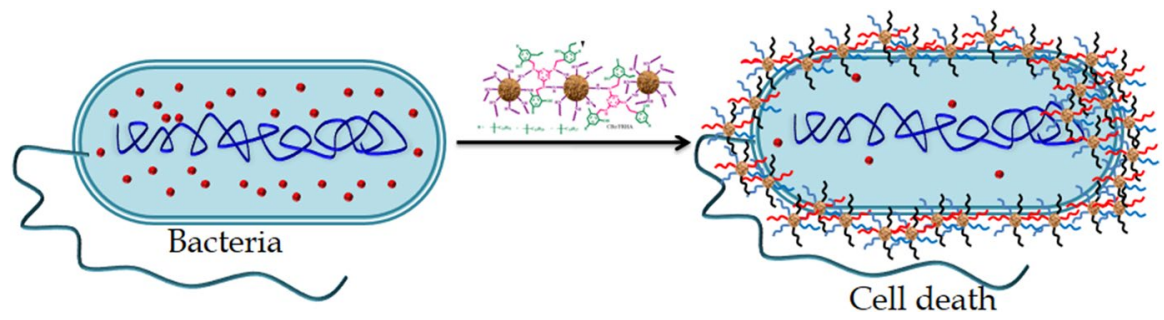

Fig. 14 Proposed images of cell death of bacteria

to improve the thermal, flame retardant, antimicrobial and dielectric properties. The results from the thermal properties confirm that the curing temperature of neat $\mathrm{CBz}$ benzoxazine was considerably lower $\left(229^{\circ} \mathrm{C}\right)$ than that of aniline-based cardanol-benzoxazine $\left(275^{\circ} \mathrm{C}\right)$ due to the presence of heterocyclic core (melamine) in the $\mathrm{CBz}$ benzoxazine. The $20 \mathrm{wt} \%$ FRHA-reinforced CBz/FRHA possesses the higher values of glass transition temperature $\left(T_{\mathrm{g}}=145^{\circ} \mathrm{C}\right)$ and char yield (36\%) values than those of neat $\mathrm{CBz}$. The results obtained from microbial studies indicate that the FRHA-incorporated $\mathrm{CBz}$ polybenzoxazine exhibits an excellent antimicrobial behavior and can be used in the place of conventional composites obtained from synthetic sources. Similarly, the results from dielectric studies also ascertain that $20 \mathrm{wt} \%$ FRHA-reinforced CBz/FRHA composites exhibit the lowest values of dielectric constant (low $k=2.15$ ) and dielectric loss 
(0.0015) suggests that these material can be effectively utilized in microelectronics insulation applications.

Open Access This article is distributed under the terms of the Creative Commons Attribution 4.0 International License (http://creativecommons.org/licenses/by/4.0/), which permits unrestricted use, distribution, and reproduction in any medium, provided you give appropriate credit to the original author(s) and the source, provide a link to the Creative Commons license, and indicate if changes were made.

\section{References}

1. Biermann U, Bornscheuer U, Meier MAR, Metzger JO, Schafer HJ (2011) Oils and fats as renewable raw materials in chemistry. Angew Chem Int Ed 50:3854

2. Rio ED, Lligadas G, Ronda JC, Galia M, Meier MAR, Cadiz V (2011) Polyurethanes from polyols obtained by ADMET polymerization of a castor oil-based diene: characterization and shape memory properties. J Polym Sci Part A Polym Chem 49:518

3. Pillai CKS (2010) Challenges for natural monomers and polymers: novel design strategies and engineering to develop advanced polymers. Des Monomers Polym 13:87

4. Paramashivappa R, Kumar PP, Vithayathil PJ, Rao AS (2001) Novel method for isolation of major phenolic constituents from cashew (Anacardium occidentale L.) nut shell liquid. J Agric Food Chem 49:2548

5. Blazdell P (2000) The mighty cashew. Interdiscip Sci Rev 28:220

6. Lochab B, Shukla S, Varma IK (2014) Naturally occurring phenolic sources: monomers and polymers. RSC Adv 4:21712

7. Kanehashi S, Yokoyama K, Masuda R, Kidesaki T, Nagai K, Miyakoshi T (2013) Preparation and characterization of cardanol-based epoxy resin for coating at room temperature curing. $\mathrm{J}$ Appl Polym Sci 130:2468

8. Yagci Y, Kiskan B, Ghosh NN (2009) Recent advancement on polybenzoxazine-a newly developed high performance thermoset. J Polym Sci Part A Polym Chem 21:47

9. Hoang SL, Vu CM, Pham LT, Choi HJ (2018) Preparation and physical characteristics of epoxy resin/bacterial cellulose biocomposites. Polym Bull 75:2607

10. Manh CV, Choi HJ (2016) Enhancement of interlaminar fracture toughness of carbon fiber/epoxy composites using silk fibroin electrospun nanofibers. Polym-Plast Technol Eng 55:1048

11. Pham TD, Vu CM, Choi HJ (2017) Enhanced fracture toughness and mechanical properties of epoxy resin with rice husk-based nano-silica. Polym Sci Ser A 59:437

12. Tyman JHP (1996) Synthetic and natural phenols. Elsevier, Amsterdam

13. Attanasi OA (1983) Chemistry and industrial utilization of phenols. Chim Oggi 8:11

14. Harvey MT, Caplan C (1940) Cashew nut shell liquid. Ind Eng Chem 32:1306

15. Nguyn LT, Vu CM, Phuc BT, Tung NH (2018) Simultaneous effects of silanized coal fly ash and nano/micro glass fiber on fracture toughness and mechanical properties of carbon fiber-reinforced vinyl ester resin composites. Polym Eng Sci. https://doi.org/10.1002/pen.24973

16. Vu CM, Thanh NL, Viet NT, Jin CH (2014) Effect of additive-added epoxy on mechanical and dielectric characteristics of glass fiber reinforced epoxy composites. Polymer (Korea) 38:726

17. Patel CJ, Mannari V (2014) Air-drying bio-based polyurethane dispersion from cardanol: synthesis and characterization of coatings. Prog Org Coat 77:997-1006

18. Wazarkar K, Kathalewar M, Sabnis A (2018) Anticorrosive and insulating properties of cardanol based anhydride curing agent for epoxy coatings. React Funct Polym 122:148-157

19. Atta AM, Al-Hodan HA, AbdelHameed RS, Ezzat AO (2017) Preparation of green cardanolbased epoxy and hardener as primer coatings for petroleum and gas steel in marine environment. Prog Org Coat 111:283-293

20. Sang M, Meng Y, Wang S, Long Z (2018) Graphene/cardanol modified phenolic resin for the development of carbon fiber paper-based composites. RSC Adv. 8:24464-24469

21. Ohashi S, Iguchi D, Heyl TR, Froimowicza P, Ishida H (2018) Quantitative studies on the p-substituent effect of the phenolic component on the polymerization of benzoxazines. Polym Chem 9:4194-4204 
22. Calo E, Maffezzoli A, Mele G, Martina F, Mazzetto SE, Tarzia A, Stifani C (2007) Synthesis of a novel cardanol-based benzoxazine monomer and environmentally sustainable production of polymers and bio-composites. Green Chem 9:754

23. Vu CM, Nguyen DD, Sinh LH, Pham TD, Pham LT, Choi HJ (2017) Environmentally benign green composites based on epoxy resin/bacterial cellulose reinforced glass fiber: fabrication and mechanical characteristics. Polym Test 17:150

24. Vu CM, Nguyen DD, Sinh LH, Choi HJ, Pham TD (2018) Improvement the mode I interlaminar fracture toughness of glass fiber reinforced phenolic resin by using epoxidized soybean oil. Polym Bull 75:4769

25. Vu CM, Nguyen DD, Sinh LH, Choi HJ, Pham TD (2018) Micro-fibril cellulose as a filler for glass fiber reinforced unsaturated polyester composites: fabrication and mechanical characteristics. Macromol Res 26:54

26. Minigher A, Benedetti E, De Giacomo O, Campaner P, Aroulmoji V (2009) Synthesis and characterization of novel cardanol based benzoxazines. Nat Prod Commun 4:521

27. Rao BS, Palanisamy A (2011) Monofunctional benzoxazine from cardanol for bio-composite applications. React Funct Polym 71:148

28. Li S, Yan S, Yu J, Yu B (2011) Synthesis and characterization of new benzoxazine-based phenolic resins from renewable resources and the properties of their polymers. J Appl Polym Sci 122:2843

29. Vu CM, Sinh LH, Choi HJ, Pham TD (2017) Effect of micro/nano white bamboo fibrils on physical characteristics of epoxy resin reinforced composites. Cellulose 24:5475

30. Vu CM, Sinh LH, Nguyen DD, Thi HV, Choi HJ (2018) Simultaneous improvement of the fracture toughness and mechanical characteristics of amine-functionalized nano/micro glass fibril-reinforced epoxy resin. Polym Test 71:200

31. Raoandand BS, Palanisamy A (2012) A new thermo set system based on cardanol benzoxazine and hydroxy benzoxazoline with lower cure temperature. Prog Org Coat 74:427

32. Arumugam H, Krishnan S, Chavali M, Muthukaruppan A (2018) Cardanol based benzoxazine blends and bio-silica reinforced composites: thermal and dielectric properties. New J Chem 42:4067-4080

33. Lochab B, Indra K, Varma J, Bijwe J (2012) Sustainable polymers derived from naturally occurring materials. Therm Anal Calorim 107:661

34. Krishnadevi K, Selvaraj V (2015) Development of halogen free flame retardant phosphazene and rice husk ash incorporated benzoxazine blended epoxy composites for microelectronic applications. New J Chem 39:6555

35. Sponton M, Mercado LA, Ronda JC, Galia M, Cadiz V (2008) Preparation, thermal properties and flame retardancy of phosphorus- and silicon-containing epoxy resins. Polym Degad Stab 93:2025

36. Krishnadevi K, Nirmala Grace A, Alagar M, Selvaraj V (2014) Development of hexa (aminophenyl) cyclotriphosphazene (CPA) modified cyanate ester composites for high temperature applications. High Perform Polym 26:1

37. Van Krevelen DW (1975) Some basic aspects of flame resistance of polymeric materials. Polymer 16:615

38. Krishnadevi K, Selvaraj V (2016) Biowaste material reinforced cyanate ester based epoxy composites for flame retardant applications. High Perform Polym 28:881

39. Krishnadevi K, Selvaraj V (2017) Development of cyclophosphazene and rice husk ash incorporated epoxy composites for high performance applications. Polym Bull 74:1791

40. Lin CH, Huang SJ, Wang PJ, Lin HT, Dai HA (2012) Miscibility, microstructure, and thermal and dielectric properties of reactive blends of dicyanate ester and diamine-based benzoxazine. Macromolecules 45:7461

41. Zhang K, Zhuang Q, Liu X, Yang G, Cai R, Han Z (2013) A new benzoxazine containing benzoxazole-functionalized polyhedral oligomeric silsesquioxane and the corresponding polybenzoxazine nanocomposites. Macromolecules 46:2696

42. Vandiver J, Dean D, Patel N, Botelho C, Best S, Santos JD, lopes MA, Bondield W, Ortiz C, Biomed J (2006) Silicon addition to hydroxyapatite increases nanoscale electrostatic, van der Waals, and adhesive interactions. Mater Res A 78:1619

43. Stoimenov PK, Klinger RL, Marchi GL, Klabunde KJ (2002) Metal oxide nanoparticles as bactericidal agents. Langmuir 18:6679 
Publisher's Note Springer Nature remains neutral with regard to jurisdictional claims in published maps and institutional affiliations.

\section{Affiliations}

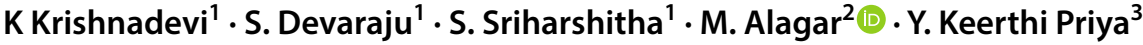

1 Polymer Composites Lab, Division of Chemistry, Department of Sciences and Humanities, Vignan's Foundation for Science, Technology and Research, Vadlamudi, Guntur 522 213, India

2 Centre of Excellence Advanced Material Manufacturing, Processing and Characterization (CoExAMMPC), Vignan's Foundation for Science, Technology and Research, Vadlamudi, Guntur 522 213, India

3 Department of Biotechnology, Vignan's Foundation for Science Technology and Research, Vadlamudi, Guntur 522 213, India 